\title{
Quality and sensory evaluation of ice-cream fortified with calcium
}

\author{
G. Rajarajan ${ }^{a}$, R. Annal Villi ${ }^{b}$, B. Mohan ${ }^{c}$ and (D) A. Irshad ${ }^{d}$ \\ aAssistant Professor, Department of Livestock Products Technology, Veterinary College and Research Institute, \\ Orathanadu-614 625, Tamil Nadu, TANUVAS. \\ bProfessor and Head, Department of Food Processing Technology, College of Food and Dairy Technology, Alamathy- \\ Koduvalli, Chennai - 600052 \\ 'Dean, Veterinary College and Research Institute, Namakkal-637 002, Tamil Nadu, TANUVAS. \\ dAssistant Professor, Meat Technology Unit, and Department of Livestock Products Technology, College of Veterinary \\ and Animal Sciences, Mannuthy-680 651
}

Corresponding author: G. Rajarajan | email: rajarajanvet@gmail.com

Co-authors: RAV: annalvilli@gmail.com ; BM: mohan.b@tanuvas.ac.in ; IA: irshad@kvasu.ac.in

Received: 21-09-2020, Accepted: 15-11-2020, Published online: 20-12-2020

\begin{abstract}
Milk is an essential dietary calcium source, with estimates from $40 \%$ up to $74 \%$ of calcium coming from dairy foods. People who avoid dairy foods usually had an inadequate nutritional intake, unless they had an adequate intake of other high calcium dietary foods. A study was conducted to enrich calcium in ice cream to counteract the deficiency. Calcium in the form of calcium citrate was supplemented at three different levels viz.500mg, 1000mg and $1500 \mathrm{mg}$ in one litre of ice cream mix. The enriched ice cream samples were subjected to sensory evaluation for its acceptance, using the 9-point hedonic scale.

Further, the sensory attributes of calcium-enriched ice cream were analyzed with the texture profile analyzer's help. The recovery percentage of calcium in the enriched ice cream was carried out by Atomic absorption spectrometry. The study concluded that calcium could be enriched in ice cream mix at a $500 \mathrm{mg}$ per litre level since it had better acceptability and thereby counteract the calcium deficiency.
\end{abstract}

Keywords: Ice Cream -Calcium- Enrichment- Sensory evaluation- Texture analysis- Stability

\footnotetext{
doi: https://doi.org/10.51128/jfas.2020.A024 | How to cite this article: Rajarajan, G., Villi, R.A., Mohan, B. and Irshad, A. 2020. Quality and sensory evaluation of ice-cream fortified with calcium. Journal of Food and Animal Sciences, 01(02): 131 - 135.

Copyright: Rajarajan et al., 2020. Open Access. This article is distributed under the terms of the Creative Commons Attribution 4.0 International License (http://creativecommons.org/licenses/by/4.0/), which permits unrestricted use, distribution, and reproduction in any medium, provided you give appropriate credit to the original author(s) and the source, provide a link to the Creative Commons license, and indicate if changes were made. The Creative Commons Public Domain Dedication waiver (http://creativecommons.org/publicdomain/zero/1.0/) applies to the data made available in this article, unless otherwise stated.
} 


\section{Introduction}

Calcium is an essential nutrient required for critical biological functions such as nerve conduction, muscle contraction, mitosis, blood coagulation, and structural support of the skeleton. Calcium enriched foods are likely to play an increasingly important role in helping consumers achieve newer calcium requirements to reduce the risk of osteoporosis. The calcium source should be well absorbed and beneficial in building peak bone mass during growth and protecting against bone loss later in life. The calcium source must also be compatible with the enriched food, which relates to the salt's solubility, the concentration of calcium in the formula, processing stability, and flavour profile (Weaver, 1998). The challenge for food manufacturers is to provide a product with high calcium content without sacrificing quality for the added health value. Commonly used calcium salts might negatively affect the taste and stability of the final product (Gerstner, 2002). Calcium and Vitamin $\mathrm{D}$ enrichment of food and dairy products has increased awareness about the importance of higher calcium and vitamin D intake (Rajarajan, 2020). Dairy products are an excellent source of dietary calcium, which can be further enriched with calcium salts to achieve higher calcium intake per serving (Vyas and Tong, 2004).

\section{Materials and Methods}

Calcium in an organic salt form as calcium citrate was used for enrichment in ice cream. The calcium citrate was added at three different levels to contain $500 \mathrm{mg}, 1000 \mathrm{mg}$ and $1500 \mathrm{mg}$ in one litre of ice cream mix before homogenization. The calciumenriched ice creams were subjected to sensory evaluation by a panel of seven members using 9 points hedonic scale (Singh et al., 2014). Then the enriched product was also subjected to texture profile analysis according to Chansathirapanich et al. (2016). The texture analysis was performed at $15^{\circ} \mathrm{C}$ using a TA.XT plus Texture Analyzer (Stable Micro System, United Kingdom). The enriched calcium in ice cream was estimated by Atomic absorption spectrometry to assess the retention (Kazi, 2015). All the statistical analyses were performed by using SPSS. The results were expressed as the mean \pm S.E., and in all applications (ANOVA) the differences were considered statistically significant at $\mathrm{P}<0.05$ and highly significant at $\mathrm{P}<0.01$.

\section{Results and Discussion}

The developed calcium citrate enriched ice cream was assessed by sensory evaluation using the 9-point hedonic scale by a semi-trained panel of seven

Table 1: Calcium enriched ice cream assessed by sensory evaluation using the 9-point hedonic scale

\begin{tabular}{|c|c|c|c|c|}
\hline Sensory attributes & Control & $\mathbf{T}_{1}$ & $\mathbf{T}_{2}$ & $\mathbf{T}_{3}$ \\
\hline Flavour & $8.625 \pm 0.078^{\mathrm{d}}$ & $8.550 \pm 0.080^{\mathrm{c}}$ & $7.725 \pm 0.101^{\mathrm{b}}$ & $6.925 \pm 0.136^{\mathrm{a}}$ \\
\hline Body \& Texture & $8.500 \pm 0.087^{\mathrm{d}}$ & $8.400 \pm 0.100^{\mathrm{c}}$ & $7.575 \pm 0.079^{\mathrm{b}}$ & $6.825 \pm 0.129^{\mathrm{a}}$ \\
\hline Colour \& Appearance & $8.100 \pm 0.112^{\mathrm{c}}$ & $8.075 \pm 0.097^{\mathrm{bc}}$ & $7.550 \pm 0.080^{\mathrm{b}}$ & $7.050 \pm 0.134^{\mathrm{a}}$ \\
\hline Melting quality & $8.400 \pm 0.106^{\mathrm{c}}$ & $8.375 \pm 0.099^{\mathrm{c}}$ & $7.400 \pm 0.078^{\mathrm{b}}$ & $6.800 \pm 0.130^{\mathrm{a}}$ \\
\hline Overall acceptability & $8.600 \pm 0.093^{\mathrm{c}}$ & $8.550 \pm 0.087^{\mathrm{c}}$ & $7.375 \pm 0.078^{\mathrm{b}}$ & $6.650 \pm 0.116^{\mathrm{a}}$ \\
\hline
\end{tabular}

Mean \pm SE with different superscripts in a row, differs significantly $(\mathrm{P}<0.05)$.

C- Control (not enriched); T1- Treatment with $500 \mathrm{mg} / \mathrm{L}$ Calcium citrate;

T2 -Treatment with $1000 \mathrm{mg} / \mathrm{L}$ Calcium citrate; T3- Treatment with 1500mg/L Calcium citrate; $\mathrm{n}=42$ for each treatment

Sensory scores based on 9-point hedonic scale, where 1: dislike extremely and 9: like extremely 
Table 2: Calcium enriched ice cream assessed by texture profile analysis

\begin{tabular}{|c|c|c|c|c|}
\hline Texture parameters & Control & $\mathbf{T}_{\mathbf{1}}$ & $\mathbf{T}_{2}$ & $\mathbf{T}_{3}$ \\
\hline Firmness (g) & $363.712 \pm 154.794^{\mathrm{a}}$ & $338.975 \pm 51.304^{\mathrm{b}}$ & $358.497 \pm 34.401^{\mathrm{c}}$ & $407.169 \pm 54.044^{\mathrm{d}}$ \\
\hline Consistency (g/sec) & 5315.251 & 5189.573 & 5684.735 \\
$\pm 3654.653^{\mathrm{d}}$ & $\pm 786.848^{\mathrm{c}}$ & $\pm 468.836^{\mathrm{b}}$ & $\begin{array}{c}6013.743 \\
\pm 1618.333^{\mathrm{a}}\end{array}$ \\
\hline Cohesiveness(g) & -312.671 & -302.963 & -149.125 & -498.341 \\
$\pm 166.421^{\mathrm{a}}$ & $\pm 100.964^{\mathrm{ab}}$ & $\pm 34.929^{\mathrm{b}}$ & $\pm 124.578^{\mathrm{ab}}$ \\
\hline $\begin{array}{c}\text { Viscosity index } \\
\text { (g/sec) }\end{array}$ & $-234.129 \pm 212.824^{\mathrm{c}}$ & $-233.110 \pm 219.267^{\mathrm{d}}$ & $-288.637 \pm 84.618^{\mathrm{b}}$ & $-295.204 \pm 139.085^{\mathrm{a}}$ \\
\hline
\end{tabular}

Mean \pm SE with different superscripts in a row differs significantly $(\mathrm{P}<0.05)$.

C- Control (not enriched); T1- Treatment with 500mg/L Calcium citrate

T2 - Treatment with 1000mg/L Calcium citrate; T3- Treatment with 1500mg/L Calcium citrate

$\mathrm{n}=6$ for each treatment

members, and the scores were presented in Table- 1.

The statistical analysis revealed that $\mathrm{T}_{1}$ showed better sensory scores than $\mathrm{T}_{2}$ and $\mathrm{T}_{3}$ and hence calcium citrate at $500 \mathrm{mg}$ per litre ice cream mix may be incorporated for enrichment in ice cream.

The enriched ice cream samples were also subjected to texture profile analysis and the results were presented in Table-2, and the results revealed that $\mathrm{T}_{1}$ was comparable with that of control ice cream than $\mathrm{T}_{2}$ and $\mathrm{T}_{3}$

The recovery of calcium citrate in the enriched ice cream was assessed by Atomic absorption spectrometry and the results were presented in Table-3. The $\mathrm{T}_{1}$ had better recovery than $\mathrm{T}_{2}$ and $\mathrm{T}_{3}$ and hence calcium citrate could be incorporated at $500 \mathrm{mg}$ per litre ice cream mix for enrichment in ice cream. The findings were in accordance with Chansathirapanich et al. (2016).

Figure 1. Recovery of calcium from ice cream enriched with calcium citrate by Atomic absorption spectrometry

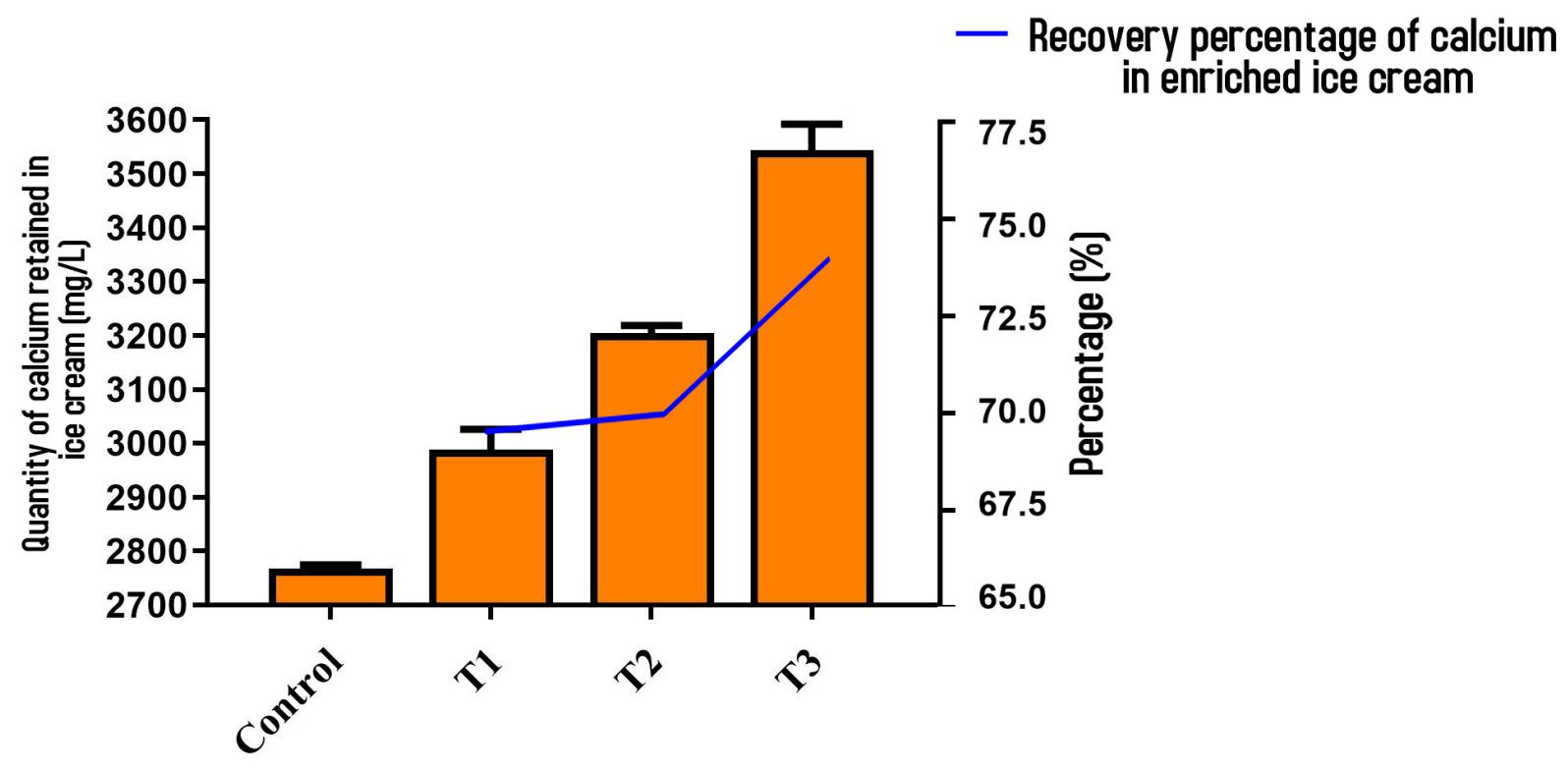


Table 3: Recovery of calcium from ice cream enriched with calcium citrate by Atomic absorption spectrometry

\begin{tabular}{|c|c|c|c|c|}
\hline Parameters & Control & $\mathbf{T}_{1}$ & $\mathbf{T}_{2}$ & $\mathbf{T}_{3}$ \\
\hline $\begin{array}{c}\text { Quantity of calcium } \\
\text { retained in ice cream } \\
(\mathrm{mg} / \mathrm{L})\end{array}$ & $2767.500 \pm 6.980$ & $2987.500 \pm 38.261$ & $3204.667 \pm 13.703$ & $3543.500 \pm 48.672$ \\
\hline $\begin{array}{c}\text { Recovery percentage in } \\
\text { enriched ice cream }\end{array}$ & $73.34 \%$ & $70.02 \%$ & $69.79 \%$ \\
\hline
\end{tabular}

C- Control (not enriched);

T1- Treatment with $500 \mathrm{mg} / \mathrm{L}$ Calcium citrate

T2 - Treatment with $1000 \mathrm{mg} / \mathrm{L}$ Calcium citrate; T3- Treatment with 1500mg/L Calcium citrate $\mathrm{n}=6$ for each treatment

\section{Conclusions}

Adequate calcium intake has been demonstrated to reduce the risk of chronic diseases such as osteoporosis, hypertension, colon cancer, breast cancer, kidney stones, polycystic ovary syndrome and ovarian cancer. Several advanced nations have launched nationwide fortification programs to improve children's calcium status, elderly persons, and post menopause women. Foods are rarely enriched with calcium in India. Hence an attempt has been made to enhance calcium citrate in ice cream at $500 \mathrm{mg}$ per litre of the mix which evinced better overall sensory acceptability, texture profile and retention in the finished product. Therefore it might be concluded that calcium citrate enriched ice cream could be a mass intervention to address calcium deficiency.

\section{Authorship contribution statement}

G. Rajarajan: Conceptualization, Methodology, Formal analysis, Investigation, Writing - original draft, Writing - review \& editing, R. Annal Villi: Conceptualization, Methodology, Writing - review \& editing. B. Mohan: Conceptualization, Methodology, Writing - original draft, Writing - review \& editing. Irshad A: Conceptualization, Methodology, Writing - original draft, Writing - review \& editing.

\section{Acknowledgments}

All the authors acknowledge and thank their respective Institutes and Universities.

\section{Funding}

No specific funding for the reserch work other than the $\mathrm{PhD}$ research grand from Tamil Nadu Veterinary and Animal Sciences University.

\section{Declaration of Competing Interest}

All authors declare that there exist no commercial or financial relationships that could, in any way, lead to a potential conflict of interest.

\section{Reference}

Chansathirapanich, W., Ngamchuachit, P. and Tansawat, R. 2016. Effect of fat content on characteristics of ice cream fortified with calcium and vitamin D3. Thai Journal of Pharmaceutica Sciences. 40 (3): 132-138.

Gerstner G. 2002. Calcium lactate gluconateThe innovative solution for extra calcium. Innovations Food Technol., 16: 1-3.

Kazi, A.M. 2015. Mineral analysis of milk through atomic absorption spectroscopy and their biological role in human life. Int'l Journal of Advances in Chemical Engg., er Biological Sci., 2: 113-115.

Rajarajan, G., Villi, R.A., Mohan, B. and Irshad, A. 2020. Optimization of enrichment levels of vitamin D in Ice cream. Journal of Food and Animal Sciences, 01(01): 28-32. doi: https:// doi.org/10.51128/jfas.2020.A005 
Singh, A, Bajwa, U. and Goraya, R.K. 2014. Effect of storage period on the physicochemical, sensory and microbiological quality of bakery flavoured ice cream. Int. Journal of Engineering Research and Applications. 4(8): 80-90.

Vyas H.K and Tong P.S. 2004. Impact of source and level of calcium fortification on the heat stability of reconstituted skim milk powder. J. Dairy Sci., 87:1177-1180.

Weaver, C.M. 1998. Calcium in food fortification strategies. Int. Dairy J., 8: 443-449. 